\title{
THE MINI SEINER FLEET OF THE NORTH JAVA COAST: A Case Study of Their Fishing Activities
}

\author{
Jean Marc Ecoutin*) and Dharmadi*)
}

\begin{abstract}
Fishing effort is often a difficult parameter to identify in halieutic studies and even more so if the study involves coastal and artisanal fishing spread along a coast more than $1,000 \mathrm{~km}$ long. This is the case of the study of the mini seiner fleet operating in the Java Sea. In order to estimate this descriptive parameter of the fishing effort, it has been suggested to use the method of calculating the average activity rate and at the expense of given on certain hypotheses, to translate these rates into estimates of the number of fishing trips. This article offers a first global approach of the mini seiner fleet operating in the Java Sea from ports located on the north coast of the island of Java. It is thus demonstrated that this fleet's operating activities although more or less significant, were uninterrupted all through the year 1995, the landmark year for this study. This study also described the first reason for the heterogeneity of the fleet from the dynamics of utilization of the landing ports by mini seiner fishing units.
\end{abstract}

KEYWORDS: fishing activity, fleet dynamic, artisanal fishery, purse seine, Java Sea, Indonesia.

\section{INTRODUCTION}

From the definition by Poinsard and Le Guen (1975) adapted by Laurec and Le Guen (1981), the fishing effort applied to a stock of aquatic animals is a measure of all the different methods used to catch this stock by the fisherman during a specific time interval. This definition implies that one must take into consideration the number of vessels and their characteristics, the fishing gears used, the level of activity and the human capacities in play, etc (Laurec \& Le Guen, 1981). According to these authors, the fishing effort therefore corresponds to a quantification of the fishing activity in a time interval that relates to the exploitation of one stock or unit of management (Laurec \& Le Guen, 1981) taking into consideration isolation and homogeneity hypotheses.

For artisanal or coastal fishing, the study of the fishing effort is complicated by the heterogeneous nature of this fishing effort, by the difficulty of setting standards in order to integrate the different fleets of artisanal fishery and by the relationship of this activity between different target species and a sharing of the stocks between artisanal and industrial fisheries (Charles. Dominique, 1991). The study of the fishing activity conducted on the whole of the artisanal fishery, or on a stratum there of, aimed at understanding the importance of the activity deployed either by a global approach of all the fishing units, or on an individual basis by fishing unit or group of fishing units.

By using this approach, the entire artisanal fishery can be characterized by the potential fishing units in activity, by an average number of trips by unit, by the number of days in activity and by the average or individual length of fishing units. It is also possible to establish a diagram that describes the activity by days worked and idle days and possibly explaining the reasons of inactivity of both short and long duration.

The estimated parameters are indicators of the dynamics of each of the different areas of artisanal fishery. They allow the geographic and temporal variations of these areas to be identified and to estimate their evolutionary capacities.

In the Java Sea, the mini seiner fleet can be compared to a fleet of artisanal fishery: the numerical potential is greater than 1,500 units (Potier \& Sadhotomo, 1995); the number of landing points is significant, more than 80 (Ecoutin et al., 1997); the possibility of rapidly changing the landing site introduces a major difficulty in following individual fishing units (Hariati et al., 1995); the presence among this fleet of vessels in a variety of shapes describes a notion of heterogenity and the possibility of partitioning

$\begin{array}{ll}* \text { *) } & \text { IRD-HEA, BP 5045, } 34032 \text { Montpellier Cedex 1, France } \\ \text { Researcher of the Research Institute for Marine Fisheries, Jakarta }\end{array}$ 


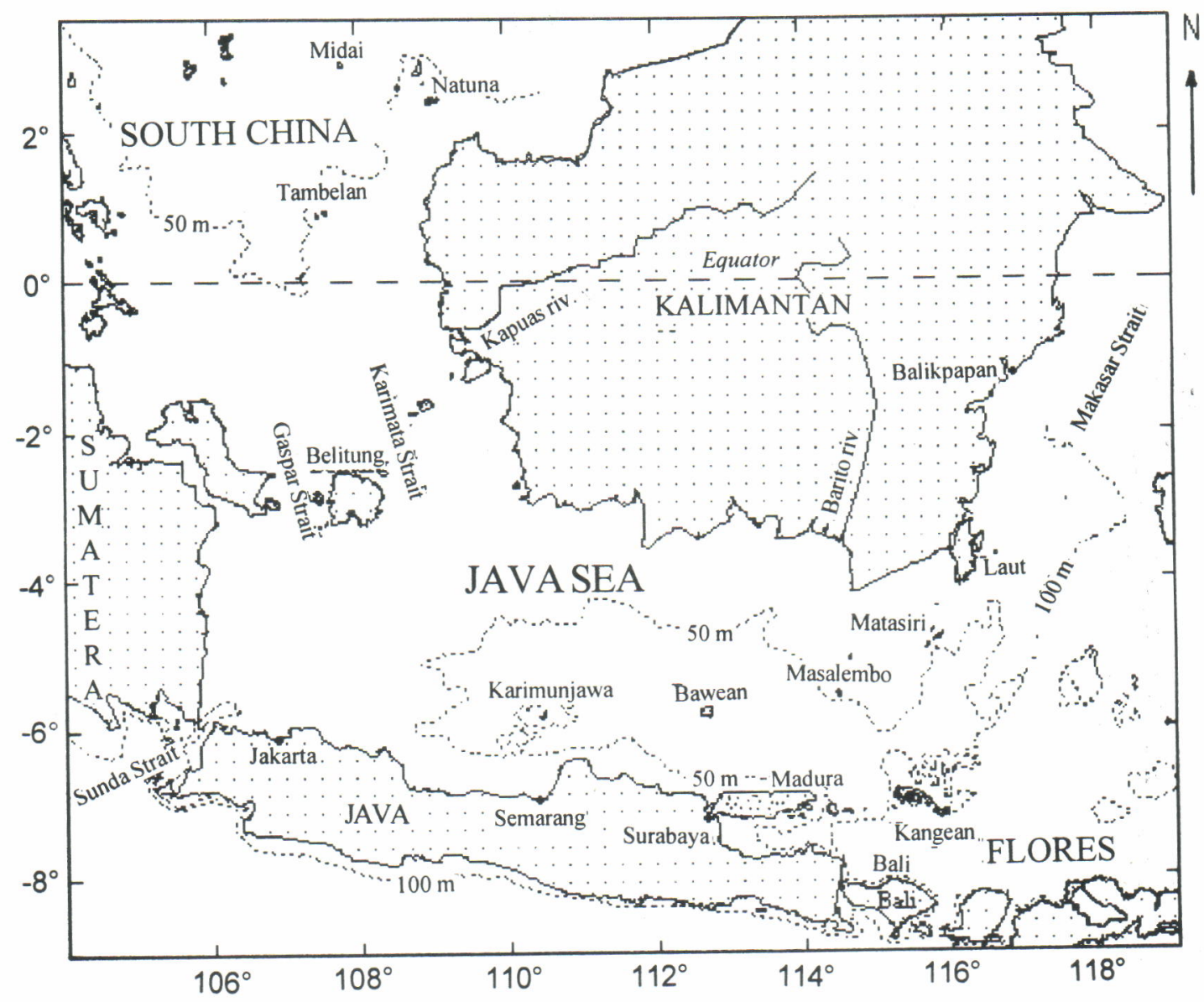

Figure 1. The Java Sea and its surroundings.

this fleet into more homogeneous subgroups (Wijopriono et al., 1996; Ecoutin et al., 1997).

In order to estimate the fishing effort by mini seiners operating in the different areas of the north shore of the Island of Java (Figure 1), by studying their activities, a regular survey of a sample of fishing units would have been necessary. Because of the significant number of the fleet and a lack of time to complete the study, only a global approach could be accomplished. Nevertheless, by this global approach, it is possible to define certain descriptive parameters useful for a first approach to the fishing activity such as the number of active days during a year, explanations for the main fishing idleness and information on the spatiotemporal variability of the distribution of this activity. This is not sufficient to translate the results obtained by the units of this fleet into an estimate of the total catch, but it does allow the completion of certain hypotheses to estimate a conversion factor of the results into total catches.

\section{MATERIALS AND METHODS}

\section{Presentation of the Ports of the Study}

Daily listings of landings by mini seiners were used to complete the study. During 1995 , these listings were recorded in eight important ports on the north shore of Java (Figure 2). Different censuses of the mini seiner fleet operating in the Java Sea (Ecoutin et al., 1997; Jung, 1998) were used to make this choice. The sampling plan included a ninth location, the port of Brondong located in the province of East Java (Figure. 2. no. 8). This port was the subject of a specific monograph (Luong, 1997) and its results could not be taken into account for this work.

From West to East, these entries were recorded in:

* Eretan Wetan (Figure 2, no. 1), the only port of the study located in the province of West Java, is a landing and commercial destination for fish from fleets using different fishing techniques: gillnets, Danish seines, mini seines. In 1994. the 


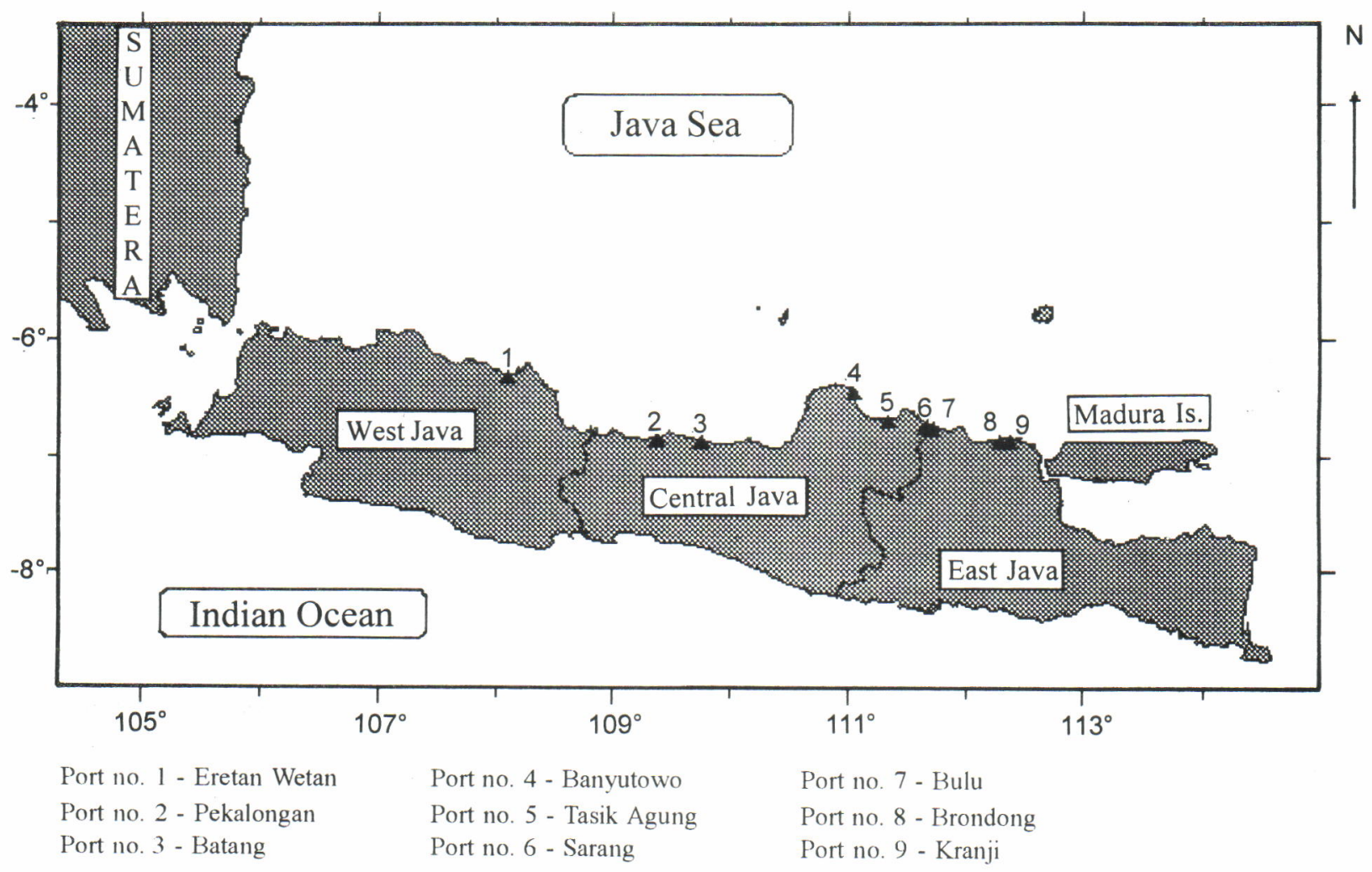

Figure 2. Geographical location of main ports of inquiries in 1995.

units of medium seiners unloaded more than 2,000 tons of pelagic species at this location, or $5 \%$ of the total landings by this fleet (Potier et al., 1995). This study location is both an auction place (TPI or Tempat Pelelangan Ikan) and a village cooperative (KUD or Koperasi (nnit Desa). It is a representative of the neighbouring villages for the study of mini seiners of the Java Sea.

* Pekalongan (no. 2) is the largest fishing port in the province of Central Java. It is part of an administrative structure grouping the principal ports of the Indonesian archipelago (PPN or Pelabuhan Perikanan Nusantara). Several auction places operate in this port with one that only deals with landings of mini seiner units. Pekalongan is the principal landing port for the fleet of large and medium seiners with approximately $50 \%$ of the landings of large seiners and $70 \%$ by the medium seiner units (year 1994, Potier et al., 1995).

* Batang (no. 3), not very far from the previous port, is a TPI where large, medium and small seiners exploiting the stock of pelagic fish of the Java Sea are unloaded.

* Banyutowo, also called Tayu (no. 4), is a small TPI situated in north west of the Bay of Rembang.
The fishing units from the villages located between Rembang and Sarang regularly visit this port. Mini seiners dock at the end of a long pier built on a beach where the water level is very low.

* Tasik Agung (no. 5) is one of the auction places of the village of Rembang. This TPI is different in that it trades pelagic fish caught mainly by mini seiner units and secondly by large and medium seiners (57 landings for 2,300 tons in 1994 or $1.5 \%$ of the total catches by this fishing fleet, Potier et al., 1995).

* Sarang (no. 6) is the more eastern TPI of this study for the province of Central Java. Many fishing techniques were observed there. For this reason, the port of Sarang can be compared to that of Eretan Wetan (no. 1).

* Bulu (no. 7) is a landing place located in the province of East Java. It is different in that the mini seiner units that unload their catch here are almost exclusively originated from this village. A few fishing units registered in Bulu moved to other locations on the north shore of the island of Java during the year. 
* Kranji (no. 9) is a small TPI located in the east of Brondong port, where fishing units using many artisanal fishing techniques land (Luong, 1997)

\section{Presentation of the Surveys}

Each sale of a fraction of a fish load made by the mini seiner fishing units was recorded by the administration of the TPI in a book called buku bakul. The different listings were then grouped by fishing unit and recorded on specific sheets for this study. The type of data collected on these pages was information needed to identify the fishing unit (name of the boat, name of the owner, the captain, origin of the fishing unit), information on the fishing trip (fishing location, duration, possible use of fishing aggregating device) in addition to contents of the catch by category of species. Usually, 6 and 8 categories of species were written up. This content was valued by weight and often by economic value.

Comparison between the lists of fishing units on these study sheets anad the data in the buku bakul (description by unit sale, daily sales for each unit that landed) showed that there were no differences in the numbers of mini seiners that arrived each day. The information recorded by each TPI was therefore correctly carried forward in the data acquisition chain of this study.

\section{Unit of observation}

The landing yielded in one fishing unit of a fishing trip as the basic element in the analysis of fishing activity, represented the unit of observation. Because the unit of observation chosen was the landing of catches recorded by the TPI and also as an indicator of a fishing trip, there existed some bias for the fishing trips whose landings were not recorded by the TPI: catches of small quantity, direct sales to a preferred buyer.

In addition, the choice of this unit of observation, which was based on a fishing trip, did not allow the extrapolation of the fishing activity of mini seiners into number of days at sea. This latter parameter was often considered a more precise indicator of the level of fishing activity. Depending on the landing location and the fishing seasons, the duration of a trip to sea could vary from a few hours to 3 or 4 days. In a few cases, the length of a trip could be even greater; this was the case of mini seiner units that sold their catch directly at sea to specific ships, the gendong boat (Luong, 1998). These gendong boats sold later the catches on Brondong harbour (Luong, 1997).
In 1995 , more than 25,500 entries were recorded in the eight villages described above. Two of them were not taken into consideration in this study of fishing activity. One was the TPI in Batang (no. 3 in Figure 2) where the data were not validated and the other was the village of Bulu (no. 7, Figure 2) where the data for the year 1995 were too incomplete to be able to conduct this type of analysis.

\section{RESULTS AND DICUSSIONS}

\section{Global Analysis of the Activity}

Of the remaining six villages in the sample (one in West Java, four in Central Java and one in East Java) and after validating the inquiries (approximately $0.5 \%$ of the inquiries were invalidated), the sample contained more than 20,100 entries spread unevenly over the 12 months of the year (Table 1).

\section{Analysis of the Activity Calendar}

The number of inquiries (entries) recorded each day varied from 0 (value observed 11 times during the year or $3 \%$ ) to 160 inquiries (observation of March $\left.29^{\text {th }}, 1995\right)$. The average number of daily entries recorded was 55 with a standard deviation of 35 . The histogram of the distribution of the number of daily entries did not show any specific shape to the distribution of the values between 15 and 90 entries per observation day (Figure 3).

A little more than $10 \%$ of the observations corresponded to days with no or few entries (less than 10 landings recorded). They were defined as days or periods with low activity. In the same manner, approximately $10 \%$ of the observations corresponded to days or periods with high activity with a maximum of entries recorded (more than 100 daily inquiries, Figure 3).

\section{* Study of the periods with low activity}

During 1995, four main periods of low activity were observed (Table 1, days circled by a thick line). These sequences were formed with a minimum of six consecutive days of reduced activity following the definition stated above. They are the periods: a) from January 12 to 18 with an average of 3.5 landings per day, b) from February 7 to 13 , 3 landings per day, c) from March 1 to 8, 1.5 daily landings and 6 consecutive days without a single inquiry, and d) from December 6 to 11, to which period we can add the 13 , with a little less than 2.5 daily landings and three days with no entries. 
Table 1. General activity calendar of mini seiner fishing units.

\begin{tabular}{|c|c|c|c|c|c|c|c|c|c|c|c|c|c|}
\hline \multirow{2}{*}{ Day } & \multicolumn{12}{|c|}{ Month (1995) } & \multirow{2}{*}{ Total } \\
\hline & 1 & 2 & 3 & 4 & 5 & 6 & 7 & 8 & 9 & 10 & 11 & 12 & \\
\hline 1 & 47 & 13 & 4 & 121 & 116 & 76 & 15 & 66 & 55 & 62 & 104 & 73 & 752 \\
\hline 2 & 68 & 16 & 0 & 114 & 88 & 75 & 16 & 89 & 70 & 59 & 69 & 36 & 700 \\
\hline 3 & 53 & 54 & 0 & 123 & 71 & 67 & 19 & 82 & 32 & 71 & 62 & 31 & 665 \\
\hline 4 & 58 & 11 & 0 & 111 & 59 & 34 & 88 & 98 & 78 & 66 & 43 & 53 & 699 \\
\hline 5 & 68 & 23 & 0 & 86 & 70 & 52 & 89 & 74 & 68 & 65 & 41 & 44 & 680 \\
\hline 6 & 65 & 19 & 0 & 43 & 61 & 33 & 75 & 63 & 76 & 55 & 46 & 3 & 539 \\
\hline 7 & 52 & 8 & 0 & 6 & 36 & 21 & 51 & 76 & 76 & 43 & 48 & 3 & 420 \\
\hline 8 & 34 & 1 & 8 & 1 & 48 & 15 & 36 & 65 & 55 & 27 & 74 & 0 & 364 \\
\hline 9 & 27 & 7 & 43 & 37 & 44 & 15 & 40 & 64 & 48 & 33 & 36 & 0 & 394 \\
\hline 10 & 28 & 0 & 28 & 138 & 7 & 16 & 33 & 59 & 42 & 38 & 38 & 0 & 427 \\
\hline 11 & 41 & 2 & 31 & 119 & 7 & 29 & 47 & 53 & 51 & 78 & 38 & 2 & 498 \\
\hline 12 & 8 & 1 & 96 & 36 & 32 & 33 & 53 & 66 & 58 & 59 & 49 & 18 & 509 \\
\hline 13 & 1 & 2 & 88 & 65 & 70 & 21 & 23 & 41 & 47 & 32 & 72 & 9 & 471 \\
\hline 14 & 4 & 19 & 68 & 55 & 35 & 18 & 35 & 59 & 32 & 70 & 104 & 12 & 511 \\
\hline 15 & 2 & 20 & 47 & 43 & 39 & 10 & 28 & 56 & 36 & 64 & 106 & 43 & 494 \\
\hline 16 & 0 & 13 & 26 & 25 & 24 & 17 & 8 & 86 & 38 & 91 & 125 & 43 & 496 \\
\hline 17 & 4 & 36 & 6 & 37 & 19 & 20 & 33 & 60 & 85 & 108 & 89 & 36 & 533 \\
\hline 18 & 6 & 24 & 11 & 36 & 4 & 31 & 43 & 26 & 113 & 88 & 80 & 41 & 503 \\
\hline 19 & 26 & 48 & 18 & 39 & 15 & 54 & 37 & 14 & 108 & 106 & 77 & 55 & 597 \\
\hline 20 & 21 & 40 & 8 & 35 & 25 & 40 & 97 & 88 & 128 & 116 & 83 & 83 & 764 \\
\hline 21 & 17 & 92 & 55 & 53 & 55 & 29 & 66 & 91 & 140 & 73 & 52 & 67 & 790 \\
\hline 22 & 14 & 59 & 66 & 63 & 56 & 58 & 76 & 114 & 99 & 107 & 127 & 68 & 907 \\
\hline 23 & 6 & 36 & 104 & 57 & 38 & 87 & 60 & 90 & 108 & 112 & 94 & 84 & 876 \\
\hline 24 & 8 & 52 & 137 & 97 & 61 & 110 & 45 & 78 & 98 & 101 & 60 & 72 & 919 \\
\hline 25 & 2 & 69 & 157 & 93 & 49 & 110 & 36 & 92 & 100 & 150 & 38 & 73 & 969 \\
\hline 26 & 17 & 67 & 119 & 73 & 95 & 93 & 62 & 95 & 86 & 148 & 19 & 98 & 972 \\
\hline 27 & 57 & 22 & 113 & 87 & 79 & 67 & 60 & 92 & 105 & 82 & 24 & 85 & 873 \\
\hline 28 & 38 & 15 & 139 & 64 & 56 & 41 & 73 & 84 & 109 & 44 & 22 & 76 & 761 \\
\hline 29 & 19 & & 160 & 43 & 90 & 34 & 71 & 81 & 74 & 28 & 111 & 68 & 779 \\
\hline 30 & 20 & & 141 & 73 & 66 & 21 & 75 & 71 & 73 & 78 & 84 & 70 & 772 \\
\hline 31 & 55 & & 116 & & 66 & & 39 & 60 & & 140 & & 40 & 516 \\
\hline Total & 866 & 769 & 1789 & 1973 & 1581 & 1327 & 1529 & 2233 & 2288 & 2394 & \begin{tabular}{|l|}
2015 \\
\end{tabular} & 1386 & 20150 \\
\hline Average & 27.9 & 27.5 & 57.7 & 65.6 & 51 & 44.2 & 49.3 & 72 & 76.3 & 77.2 & \begin{tabular}{|l|}
67.2 \\
\end{tabular} & 44.7 & 55.2 \\
\hline
\end{tabular}

The second and third periods correspond to important religious holidays (Table 2): the beginning of fasting day Ramadhan for the second period and the end of the fasting month and the Idul Fitri holiday at the beginning of March. The two other periods can not be explained by religious or civil events. One of the explanations given by the fishermen related these periods of low activity to the full moon phases during the rainy season, these conditions would therefore not be favorable for catching fish. One other is that, in Indonesia each year, fishermen organize some traditional celebrations named pesta laut (celebration of the sea). They last a week but the date of these celebrations are different between each village.

Of the remaining days of the year where the fishing activity seemed reduced, May 10 and 11 correspond to the Idul Adha holiday (Table 2). 


\section{J.M. Ecountin and Dharmadi}

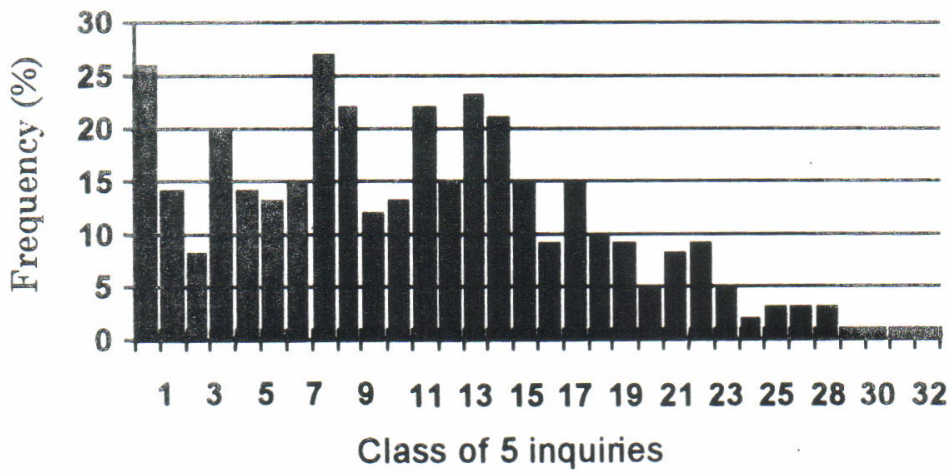

Figure 3. Distribution of the number of daily entries number of boats land-

Table 2. Relationship between the periods of low activity for the mini seiner fishing units (X less than 11 entries; XX less than 6 entries; XXX no entries) and hypotheses.

\begin{tabular}{|c|c|c|c|c|c|c|c|c|c|c|c|c|}
\hline \multirow{2}{*}{ Day } & \multicolumn{12}{|c|}{ Month (1995) } \\
\hline & 1 & 2 & 3 & 4 & 5 & 6 & 7 & 8 & 9 & 10 & 11 & 12 \\
\hline 1 & In & & $\mathrm{XX}$ & & & & & & & & & \\
\hline 2 & & & $\mathrm{XXX}$ & & & & & & & & & \\
\hline 3 & & & Xivex & & & & & & & & & \\
\hline 4 & & & Xex & & & & & & & & & \\
\hline 5 & & & $X X X$ & & & & & & & & & \\
\hline 6 & & & $\overline{X X X}$ & & & & & & & & & $\mathrm{XX}$ \\
\hline 7 & & $\mathbf{X}$ & XXX & $\mathbf{X}$ & & & & & & & & $x x$ \\
\hline 8 & & $\mathrm{XX}$ & $\mathbf{X}$ & XX & & & & & & & 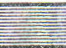 & $\mathrm{XXX}$ \\
\hline 9 & & $\mathrm{X}$ & & & $\bar{X}$ & & & 㮔 & & $\underline{E}$ & & $\mathrm{XXX}$ \\
\hline 10 & & $\overline{X X X}$ & & & $X$ & & & & & & & $\mathrm{XXX}$ \\
\hline 11 & & $\mathrm{XX}$ & & & & & & $\underline{\underline{n e n}}$ & & & & $\mathrm{XX}$ \\
\hline 12 & $\mathbf{x}$ & $\mathrm{XX}$ & & & & & & & & & & \\
\hline 13 & $\mathrm{XX}$ & $\mathbf{X X}$ & & & & 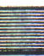 & & & & & & $\mathrm{X}$ \\
\hline 14 & $\mathrm{XX}$ & & & & & & & & & & & \\
\hline 15 & $\mathbf{X X}$ & $\sqrt{15}$ & & $\underline{\underline{15}}$ & 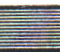 & & & & & & & \\
\hline 16 & $\mathbf{X X X}$ & & & & & & $\bar{X}$ & & & & & \\
\hline 17 & $x \times$ & & $\mathrm{X}$ & & & & & IIIIIII) & & & & \\
\hline 18 & $\mathrm{X}$ & & & & $\mathbf{X X}$ & & & & & & & \\
\hline 19 & & & & & & & & & & & & \\
\hline 20 & & & $\mathbf{X}$ & & & & & & & & & \\
\hline 21 & & & & & & & & & & & & \\
\hline 22 & & & & & & & & & & & & \\
\hline 23 & $\mathrm{X}$ & & & & & & & & & & & \\
\hline 24 & $\mathrm{X}$ & & & & & & & & & & & \\
\hline 25 & $\mathrm{XX}$ & & & & 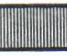 & & & & & & & \\
\hline 26 & & & & & & & & & & & & \\
\hline 27 & & & & & & & & & & & & \\
\hline 28 & & & & & & & & & & & & \\
\hline 29 & & & & & & & & & & & & \\
\hline 30 & & & & & & & & & & & & \\
\hline 31 & & & & & 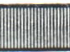 & & & & & & & \\
\hline
\end{tabular}


Finally, it must also be mentioned that except for July 16 , there were no other days of low activity between the months of June and November.

\section{* Study of the periods with strong activity}

During 1995, three main periods of high fishing activity were observed (slashed boxes in Table 1): from March 23 to the beginning of April, with 13 consecutive days, the second half of September with 8 non consecutive days, and the second half of October also with 8 non consecutive days. There were no days of strong activity observed in January (maximum observed, 68 entries), February (92), July (97) and December (98). A few days meeting the criteria for strong fishing activity were found on an isolated basis during the months of April, May and June and between August and November in addition to the periods mentioned above.

\section{* The fishing activity}

In 1995 , the mini seiners operated all year long (only $3 \%$ of days with no landings) on a more or less regular basis. This annual calendar of the fishing activity could be broken down into different main periods.

The period between the beginning of December and March 20 corresponded to a period of low activity for mini seiner units. This low activity was explained by two main phenomenas the first explanation related to Ramadhan, the Moslem fasting month during which the general activity of the country was reduced. In 1995, this period was in February and March. This explanation was not a seasonal constant as the dates of this holiday change from year to year. The second explanation was of a seasonal nature, during the full moon phase and during the rainy season, especially but also to unfavourable environmental conditions for fishing activity (wind, waves, swells, currents, desalinization of the coastal border ) lower catches.

In 1995, the period between mid-March and mid-April was a period of strong and constant activity.

From mid-April to the beginning of August, the activity varied greatly from days of big activity to low activity. The average number of landings was slightly greater than the number calculated during the rainy season. The fishermen justified this strong variability of their activity to local climatic conditions that could disturb the fishing activity (Allain, 1996).
The last period, from the beginning of August to the end of November, corresponded to a period of very high activity. No days of reduced activity were observed and the average number of daily entries recorded was greater than 70 .

\section{Variability of the activity due to the lunar cycle}

At first glance of Table 2, there were no obvious relationship between the days of weak activity and the full moon periods. However, compared to an average lunar cycle, these days were spread over most of the lunar days, but $60 \%$ of days without much activity were grouped between the five days before and four days after the full moon. The remaining days corresponded to the Idul Fitri period, a holiday which always falls on a new moon phase.

The days or periods with strong activity usually occurred, on a lunar month cycle, between the 8 th and $16^{\text {th }}$ day, therefore surrounding the new moon phase ( $79 \%$ of observations). No days of this kind were observed during the week surrounding a full moon.

From the result of two observations on daily trips which based on lunar day, it was found that the evolution of fishing curve activities had been inter-correlated with seasonal effect. The correlation could be seen from two phenomenas of day fishing activities, i.e.: the fishing activities on lunar moon which was eight to twenty five days, and around the full moon which was less than eight days. (Figure 4). These observations seemed to contradict to the appearance of an absence of lunar effect on the variation of the activity of mini seiners. However, temporal series greater than one year must be used to test this phenomenon and determine whether there exist. a real lunar effect affecting the behavior of fishermen, whether it was a climatic event related to the lunar effect or whether the rainy season was considered a resting season.

\section{Analysis by Landing Site}

The analysis of the fishing activity of mini seiners by landing site is presented from West to East.

\section{* Eretan Wetan}

Eretan Wetan is a constant and regular landing site throughout the year since activities at this TPI were observed in $93 \%$ of days during the year of 1995 (Table 3). 


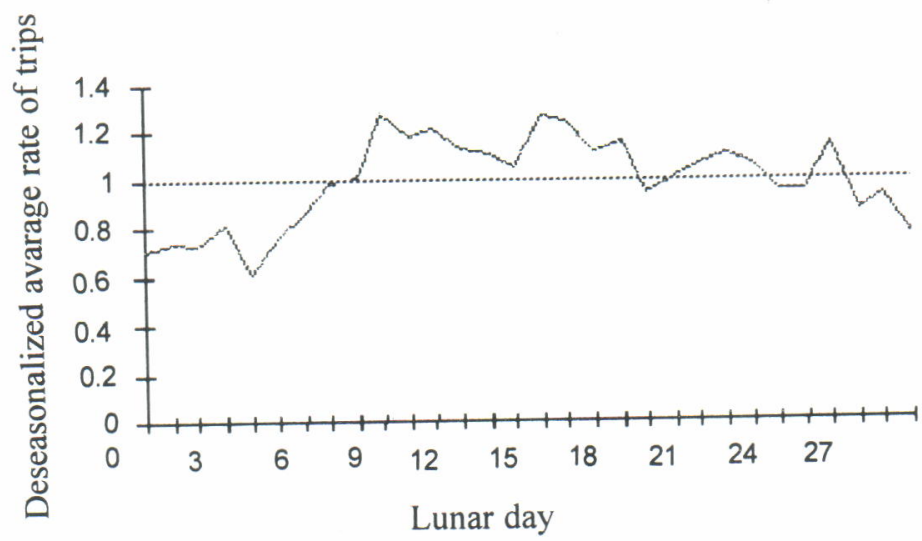

Figure 4. The deseasonalized average rate of trips by lunar day (year 1995, all ports).

Approximately $70 \%$ of days with no landings were within the four periods of weak activity for mini seiners (2.1) and the remaining days were either before or after these same periods.

More precisely, the general activity at the auction place in Eretan Wetan, whatever the fishing techniques used, was reduced during two periods (January 15-24 and December 5-18) corresponding to two periods of inactivity observed for the mini seiner fleet. This seemed to confirm that these two periods were not favorable for coastal fishing activities.

The fishing units recorded at the auction place in Eretan Wetan used diverse fishing techniques: gillnets, Danish seines, mini seines. Although the maximum entries recorded for one day was close to 50 , it seemed that this auction place saturated at $22 \cdot 25$ daily landings. All fleets included.

In 1995. mini seiner units landed at this port were only two thirds of the working days of the auction place with an average number of daily landings of 3.35 calculated for a period of 216 days (Table 3). In Eretan Wetan, there were no days where a large number of mini seiners was seen landing; in general, there were less than 7 daily landings ( $95 \%$ of observations).

The study of the seasonal variation of the number of entries highlighted two main periods: (1) on one hand, from May to October $(75 \%$ of annual entries of mini seiners, Table 3) where the units landed almost every day ( $84 \%$ of working days) with an average number of landings generally greater than the annual average (3.83 observations by day studied); and (2) from December until March where the average number of landings decreased (1.83) with a small number of docking (Table 3).

\section{* Pekalongan}

During the year of 1995, in Pekalongan, entries for mini seiner fishing units were recorded less than one out of every 2 days (45\%) for an annual average of a little more than 12 daily entries (Table 3). Contrarily to the preceding port, there was a very large variability in the number of daily entries with a maximum observed of 56 . One fifth of the days observed registered more than 20 observations.

The annual activity calendar described two periods with strong landing activity of mini seiner units separated by periods with very minimal activity: (1) from March 20 to the end of June with activity of two out of every three days, and an average of 21 entries per working day; and (2) between September 15 and the end of October which having the same activity rate as the previous period but with an average number of landings per working day much lower, around 11 or 12 entries.

Between these two periods, the number of landings observed in Pekalongan was very weak (20 to $50 \%$ of working days for an average of approximately 5 entries per day). More than $90 \%$ of units that land in Pekalongan originated from towns located in the province of East Java.

One particularity of Pekalongan was the almost complete absence of landings during the week that included the full moon and periods of both high and low activity. Pekalongan was the only one of the six ports studied where the activity of fishing units measured by their landings was directly or indirectly related to the lunar cycle.

As a landing site for mini seiners, Pekalongan therefore showed a strong variability in terms of 
Table 3. Main information on the activity observed at the ports under study (Ne; number of mini seiner entries; NJe, number of days with mini seiner landings recorded; Ne/Je, average number of entries by days with entries).

\begin{tabular}{|c|c|c|c|c|c|c|c|c|c|c|c|c|c|}
\hline & \multicolumn{12}{|c|}{ Month (1995) } & \multirow{2}{*}{ Total } \\
\hline & 1 & 2 & 3 & 4 & 5 & 6 & 7 & 8 & 9 & 10 & 11 & 12 & \\
\hline \multicolumn{14}{|c|}{ Eretan Wetan } \\
\hline $\mathrm{Ne}$ & 28 & 18 & 6 & 68 & 152 & 63 & 86 & 58 & 112 & 95 & 72 & 4 & 762 \\
\hline NJe & 14 & 7 & 5 & 14 & 24 & 23 & 24 & 25 & 29 & 27 & 20 & 4 & 216 \\
\hline $\mathrm{Ne} / \mathrm{Je}$ & 2 & 2.57 & 1.2 & 4.86 & 6.33 & 2.74 & 3.58 & 2.32 & 3.86 & 3.52 & 3.6 & 1 & 3.35 \\
\hline \multicolumn{14}{|c|}{ Pekalongan } \\
\hline $\mathrm{Ne}$ & 79 & 49 & 393 & 538 & 247 & 240 & 6 & 81 & 162 & 218 & 96 & 10 & 2119 \\
\hline $\mathrm{NJe}$ & 13 & 8 & 15 & 20 & 18 & 19 & 3 & 15 & 18 & 18 & 15 & 6 & 166 \\
\hline $\mathrm{Ne} / \mathrm{Je}$ & 6.08 & 6.13 & 26.2 & 26.9 & 13.78 & 12.68 & 2 & 5.4 & 9.06 & 12.17 & 6.6 & 1.67 & 12.81 \\
\hline \multicolumn{14}{|c|}{ Banyutowo } \\
\hline $\mathrm{Ne}$ & 87 & 54 & 51 & 56 & & 38 & 53 & 90 & 120 & 170 & 151 & 66 & 936 \\
\hline NJe & 18 & 17 & 15 & 20 & & 16 & 20 & 27 & 26 & 30 & 28 & 21 & 238 \\
\hline $\mathrm{Ne} / \mathrm{Je}$ & 4.83 & 3.18 & 3.4 & 2.8 & & 2.38 & 2.65 & 3.33 & 4.62 & 5.67 & 5.39 & 3.14 & 3.93 \\
\hline \multicolumn{14}{|c|}{ Tasik Agung (Rembang) } \\
\hline $\mathrm{Ne}$ & 256 & 206 & 656 & 882 & 824 & 677 & 641 & 902 & 974 & 822 & 749 & 485 & 8143 \\
\hline NJe & 20 & 20 & 22 & 29 & \begin{tabular}{|l|}
31 \\
\end{tabular} & 30 & 31 & 31 & \begin{tabular}{|l|}
30 \\
\end{tabular} & \begin{tabular}{|r|}
31 \\
\end{tabular} & 30 & \begin{tabular}{|l|}
24 \\
\end{tabular} & 329 \\
\hline $\mathrm{Ne} / \mathrm{Je}$ & 12.8 & 10.65 & 29.91 & 30.66 & 26.81 & 22.73 & 20.81 & 29.45 & 32.77 & 26.68 & 25.27 & 20.33 & 24.75 \\
\hline \multicolumn{14}{|c|}{ 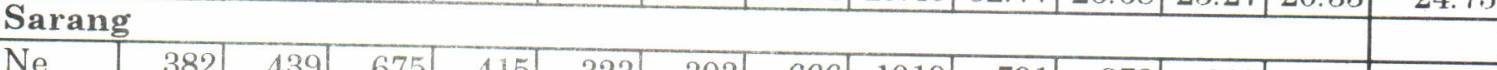 } \\
\hline $\mathrm{Ne}$ & 382 & 439 & 675 & 415 & 323 & 303 & 666 & 1010 & 791 & 873 & 812 & 732 & 7451 \\
\hline NJe & 28 & 25 & 25 & 24 & \begin{tabular}{|l|}
29 \\
\end{tabular} & \begin{tabular}{|l|}
29 \\
\end{tabular} & \begin{tabular}{|r|}
31 \\
\end{tabular} & 31 & \begin{tabular}{|l|}
30 \\
\end{tabular} & \begin{tabular}{|l|}
31 \\
\end{tabular} & 30 & \begin{tabular}{|l|}
27 \\
\end{tabular} & 340 \\
\hline $\mathrm{Ne} / \mathrm{Je}$ & 13.64 & 17.6 & 27 & 17.29 & 11.14 & 10.52 & 21.58 & 32.74 & 26.37 & 28.68 & 27.1 & 27.19 & 21.91 \\
\hline \multicolumn{14}{|c|}{ 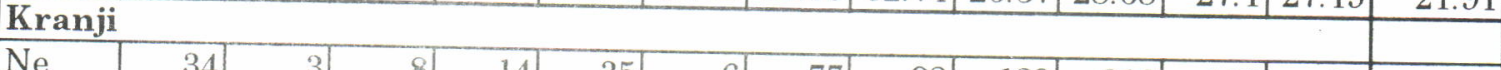 } \\
\hline $\mathrm{Ne}$ & 34 & 3 & 8 & 14 & 35 & 6 & 77 & 92 & 129 & 216 & 135 & 89 & 838 \\
\hline NJe & 12 & 3 & 8 & 9 & 13 & 5 & 25 & 23 & 29 & 28 & 25 & 19 & 199 \\
\hline $\mathrm{Ne} / \mathrm{Ie}$ & 2.83 & $1]$ & 1) & 1.55 & 2.69 & 1.2 & 3.35 & 4 & 4.45 & 7.71 & 5.4 & 4.68 & 4.21 \\
\hline
\end{tabular}

presence-absence of these units and in terms of numerical significance of their presence. This strong variability are direct and indirectly explained. by activity cycles related to the lunar cycle.

\section{* Banyutowo}

The port of Banyutowo, also called Tayu, was a small landing site for fishing units using various techniques and making fishing trips very close to the coast. It was used by the fleet of mini seiners when these units were fishing in areas near this village. A large majority of these fishing units were not from Tayu; in $1995,60 \%$ of the entries recorded were fishing units coming from Pandangan, a village located close to Tasik Agung (Figure 2) and almost 40\% from the village of Sarang (Figure 2).

In 1995. mini seiner units landed their catches a little more than 2 days out of 3 (except for the month of May that was not studied) and for each day recorded, approximately 4 units were observed arriving. Here, as in Eretan Wetan, although the activity seemed sustained all year long, the daily variation of the number of landings was weak: for $80 \%$ of days recorded less than 5 fishing units landing. For the period from August to November, the activity of these units at the port of Tayu seemed to be a little stronger both in terms of days present and the number of units landing.

No lunar effect seemed visible since the landings were observed both on full moon days and days surrounding the lunar phase.

\section{* Tasik Agung}

In 1995, at Tasik Agung more than 8,100 entries of mini seiner landings were recorded during 329 working days (Table 3). The percentage of days with entries was greater than $90 \%$. 


\section{J.M. Ecountin and Dharmadi}

This auction place therefore had regular activity all year long. Although there was a few landings by large and medium size seiners (Potier et al., 1995), this TPI only records mini seiner landings. The fishing units that unloaded their catch here were not native of this location. In $1995,41 \%$ of landings recorded were units from Pandangan (another TPI of Rembang), 48\% from Kragan and $11 \%$ from Sarang. The average number of entries per working day was around 25 entries recorded (Table 3). The variation of this parameter was strong since the daily maximum observed in 1995 was 88 entries.

During 1995, it was possible to pinpoint two main operating periods for this TPI: (1) from December to the end of February (before the Ramadhan period), where the rate of working days was close to $80 \%$ and daily activity was clearly inferior to the annual average with approximately 15 entries per day; and (2) from mid-March (after Idul Fitri) to the end of November where activity was constant, almost $100 \%$, and the monthly average number of sales recorded was close to or greater than the annual average. During the months of June and July, there was a slight decrease in the average number of daily entries.

In terms of activity, Tasik Agung, an auction place in the village of Rembang was similar to Eretan Wetan with regular and sustained annual activity. However, this activity was limited to mini seiner units whereas Eretan Wetan also records catches by pluri-technical units. Another difference between these two ports was the variability of specific landings by mini-seiners. The port located in the province of West Java (Eretan Wetan Port) had a low daily variability which was not observed in Tasik Agung.

\section{* Sarang}

Sarang, a TPI located on the eastern fringe of the province of Central Java (Figure 2, ${ }^{\circ} 6$ ), showed an activity slightly greater than in Tasik Agung as there were $93 \%$ of works days in the year 1995. In average, during the year, a little less than 22 mini seiner landings were recorded on active days of this auction place. Here, as in Tasik Agung, the daily variability was high between observations of only one landing ( 7 times during the year) and 70 landings on the same day.

As with the previous location, there were two main activity periods: (1) the first semester, with sustained activity but always below $100 \%$ (from 80 to $96 \%$ ), in which the average number of daily entries was always clearly inferior to the annual average, except in March, after the end of the Lebaran holidays, where daily activity was greater than the annual average; and (2) the second semester with $100 \%$ of working days, where daily rate of entries were greater than the annual average.

In Sarang, more than half of the landings were originated from fishing units registered in Sarang, while $44 \%$ was from fishing unit registered in Kragan and $2 \%$ registered in Rembang.

\section{* Kranji}

Kranji is a location where fishing units using various techniques of landing, with a predominance of mini seiner units. They represented two thirds of the 1,428 entries recorded in 1995 (amount calculated for the period May-December). During that year, entries were made on 247 days $(67 \%$, Table 3) and mini seiners landed during three quarters of these working days. On days with activity, an average of more than 5 mini seiners landed their catch at this auction place. These units were mainly from Kranji or bordering villages.

\section{CONCLUSIONS}

The units from the mini seiner fleet operated all year long with a few short periods of inactivity generally corresponding to the beginning and the end of the Indonesian Lebaran period. This general activity could be divided into an annual cycle with strong activity during July to November and reduced activity during the rainy season from December to March. The landing ports for the fleet of mini seiner units could be broken down into four different operating methods used: (1) Eretan Wetan, Banyutowo and to a lesser degree, Kranji: where pluri-technical fishing units land never represent large numbers of mini seiners, and those fishing units were generally migrant; (2) Sarang, Kranji: the landings were dominated by native fishing units. Mini seiner units from neighboring villages were unloaded at these busy and sometime very busy ports; (3) Tasik Agung, a constant and busy port which was a special case in that it was an auction place specialized in large, medium and mini seiner fishing units concentrates mainly in the commercialization of small pelagic species coming from other neighboring ports; and (4) Pekalongan, which did not fit into any of the above descriptions, since this port welcomes mostly migrating fishing units and the variability of the landing activity of mini seiners was very strong during the month. 
In 1995, the mini seiner units landed their catches from the Java Sea during approximately 325 to 330 days. This indicated a relatively high global activity rate for the fleet since there were more than $90 \%$ of working days during the year. Now this maximum duration of activity for the fleet, and its potential activity, must be translated into an average annual activity rate calculated by fishing unit. This future analysis will have to use the known information on the activity of the units by establishing activity calendars by fishing units and taking into consideration the peculiarities of each ports where the catches were landed. In effect, these peculiarities could determine the different exploitation dynamics by large groups of fishing units.

\section{ACKNOWLEDGEMENTS}

The present study was supported by the Pelfish Project (Java Sea Pelagic Fishery Assessment Project, ALA/INS/87/17) financed by EU which was led by Dr. J.R. Durand and Dr. J. Widodo. We wish to thank our Indonesian colleagues who were part of this project: S.B. Atmaja, S. Nurhakim, B. Sadhotomo, Suwarso, and Wijopriono.

We would like to thank all the surveyors team from different TPI from where we had to collect data. This work could not be presented without the assistance of Miss Rika who did all the part of keyboarding and validation.

\section{BIBLIOGRAPHY}

Allain, J.C. 1996. La pêche indonésienne et les minisenneurs de la Kabupaten de Rembang. Mémoire de DEA, Université Paris IV, France

Charles-Dominique, E. 1991. Halieutique et pêches artisanales : anciennes méthodes, nouvelles problématiques? (le cas de la pêche en lagune Aby, Côte-d'Ivoire). In: Durand J.R., Lemoalle J., and Weber J. (Eds.). Symp. Int. "La Recherche face à la Pêche Artisanale", Montpellier, 3-7 Juillet 1989, Paris. ORSTOM. p. 965-974.
Ecoutin, J.M., Atmaja, S.B., Potier, M., and Wijopriono. 1997. Description of the small seiner fleet in the Java Sea. Indonesian Fish. Res. J. 3(1): 47-63.

Hariati, T., Wahyono, M.M., Suwarso, and Krissunari D. 1995. North Java coast fisheries: Preliminary observations on small seine nets exploitation. In: Potier M. and Nurhakim S. (Eds.). BIODYNEX: Biology, Dynamics, Exploitation of the Small Pelagic Fishes in the Java Sea. AARD/ORSTOM. p. 185-194

Jung, A. 1998. Typologie des Mini-senneurs de la Mer de Java (Indonésie): dynamique d'une flottille artisanale. Mém. DESS 'gestion des ressources vivantes côtières', Univ. Basse-Normandie (Caen), France. 132 pp.

Laurec, A. and Le Guen, J.C. 1981. Dynamique des populations marines exploitées, tome I : concepts et méthodes. CNEXO, Rapp. Sci. Tech. 45: $118 \mathrm{pp}$.

Luong, N. 1997. The fishing harbour of Brondong (East Java, Indonesia). Java Sea Pelagic Fishery Assess. ment Project, Sci. and Tech. Ioc. 30: $68 \mathrm{pp}$.

Luong, N. 1998. Fish commercialization through the Gendong system. In: Roch J., Nurhakim S. and Widodo J. (Eds.). SOSEKIMA, Socio-economics, innovation and management of the small pelagic fishery of the Java Sea. AARD/()RST()M. p. 213-224.

Poinsard, F. and Le Guen, J.C. 1975. Observations sur la définition d'une unité d'effort de pêche applicable à la pêcherie de thon de l'Atlantique tropical africain. Rapp. PV réunion Cons. int. Explor. Mer. 168: 39. 43.

Potier, M. and Nurhakim, S. (Eds). 1995. BIODYNEX: Biology, Dynamics, Exploitation of the Small Pelagic Fishes in the Java Sea. AARD/ORSTOM. $281 \mathrm{pp}$.

Potier, M., Nurhakim, S., and Sadhotomo, B. 1995. Big purse seiners fishery statistical collection : year 1994. Java Sea Pelagic Fishery Assessment Project, Sci. and Tech. Doc. 22. $46 \mathrm{pp}$.

Potier, M. and Sadhotomo, B. 1995. Seiners fisheries in Indonesia. In: Potier M. and Nurhakim S. (Eds.). BIODYNEX: Biology, Dynamics, Exploitation of the Small Pelagic Fishes in the Java Sea. AARD/ ()RST(.)M. p. 49-66.

Wijopriono, Ecoutin, J.M., Atmaja, S.B., and Widodo, J. 1996. Heterogeneity of mini purse seine net fleet in Java Sea. Java Sea Pelagic Fishery Assessment Project, Sci. and Tech. Doc. 25: 46-51. 